Erratum

\title{
Erratum: Zhao, H.; Zhang, H.; Miao, C.; Ye, X.; Min, M. Linking Heat Source-Sink Landscape Patterns with Analysis of Urban Heat Islands: Study on the Fast-Growing Zhengzhou City in Central China. Remote Sens. 2018, 10, 1268
}

\author{
Hongbo Zhao ${ }^{1,2,3}$, Hao Zhang ${ }^{4}$, Changhong Miao ${ }^{1,2, *}$, Xinyue $\mathrm{Ye}^{5}$ and Min Min ${ }^{6}$
}

1 Key Research Institute of Yellow River Civilization and Sustainable Development \& Collaborative Innovation Center on Yellow River Civilization of Henan Province, Henan University, Kaifeng 475001, China; 10340024@vip.henu.edu.cn

2 College of Environment and Planning, Henan University, Kaifeng 475004, China

3 Department of Geography, Kent State University, Kent, OH 44242-0001, USA

4 Department of Environment Science and Engineering, Jiangwang Campus, Fudan University, 2005 Songhu Road, Shanghai 200438, China; zhanghao_fdu@fudan.edu.cn

5 Urban Informatics and Spatial Computing Lab, Department of Informatics, New Jersey Institute of Technology, Newark, NJ 07102, USA; xye@njit.edu

6 Nanjing Institute of Geography and Limnology, Chinese Academy of Sciences, Nanjing 210008, China; mmin@niglas.ac.cn

* Correspondence: chhmiao@henu.edu.cn; Tel.: +86-0371-2282-6115

Received: 29 July 2020; Accepted: 10 September 2020; Published: 11 September 2020

The authors wish to make the following corrections to this paper [1]:

The authors would like to apologize for any inconvenience caused to the readers by these changes. 1. Change in the authors' E-Mail addresses.

We would like to change the authors' E-Mail addresses on Page 1.

The fifth author's E-Mail addresses: [hzou@niglas.ac.cn] to the correct version, as follows: [mmin@niglas.ac.cn].

We apologize for any inconvenience brought to the readers.

\section{Reference}

1. Zhao, H.; Zhang, H.; Miao, C.; Ye, X.; Min, M. Linking Heat Source-Sink Landscape Patterns with Analysis of Urban Heat Islands: Study on the Fast-Growing Zhengzhou City in Central China. Remote Sens. 2018, 10, 1268. [CrossRef]

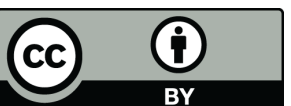

(C) 2020 by the authors. Licensee MDPI, Basel, Switzerland. This article is an open access article distributed under the terms and conditions of the Creative Commons Attribution (CC BY) license (http://creativecommons.org/licenses/by/4.0/). 